\title{
Performance Analysis of Drum Brake using Finite Element Method
}

\author{
Naresh Babu, K.Mahender
}

\begin{abstract}
The principle objective at the back of the task "Examination of Drum Brake Rotor" is to consider and determine the Drum Brake execution underneath overwhelming braking conditions and alongside these traces help within the Drum Brake rotor plan and investigation.

ANSYS 11.0 is a universally beneficial Finite Element bundles which can be utilized to decide the temperature, anxiety. ANSYS11.0 is a tool that is adaptable and financially savvy. ANSYS11.Zero utilized in the commercial enterprise to take care of a few mechanical troubles.

In this assignment, Axis-symmetric rotor Brake Drum taken into consideration for research. Rib width of $8 \mathrm{~mm}, 10 \mathrm{~mm}$ and $12 \mathrm{~mm}$ are made of Cast Iron, Aluminum and Aluminum Composite considered. A Coupled Field Analysis (Transient Thermal Analysis and Structural Analysis) is achieved to gather the temperature conveyance and Von Mises Stress. After exam Coupled subject is

Done, the chart plotted among separation and temperature. An undertaking is Made recommend the great mix of materials and rib width for Drum brake rotor, which offers an collection of low temperature and least rotor plate von mises pressure may additionally.
\end{abstract}

\section{INTRODUCTION}

A brake is instrument or hardware making use of faux frictional safety from stop the development of transferring people. While playing out this ability, brake retains capability power or motor power of transferring people. The vitality consumed by using the brake is disseminated as warmth. Warmth is misplaced which therefore discharged into the encompassing environment.

\section{LITERATUREREVIEW}

Rittner (2009) have displayed a steel framework composite packages within the resistance, aviation and mild cars. He has reasoned that the degree for MMC in all districts over hopeful and advise similarly enhancements concurrently, the willpower of the compound, reinforcing appointive and desire of parts to lessen the cost of the remaining object.

Robert (2010) has exhibited extraordinary kinds of aluminum compounds and their programs. In view of its evaluate at the development of aluminum compound, it inferred that $32.2 \%$ of the aluminum devoured inside the automobile enterprise in an change structure. Foltz et al (2010) have delivered exceptional amalgam network, fortifications and their programs in the aviation, resistance, car and gadgets bundling. They likewise brought an

Revised Manuscript Received on September 14, 2019.

Mr.Naresh Babu, Assistant Professors/ Department of Mechanical Narapally,Hyderabad, Telangana, India.

Mr.K.Mahender, Assistant Professors/ Department of Mechanical Engineering, Siddhartha Institute of Technology\&Sciences, Narapally,Hyderabad, Telangana, India. Engineering, Siddhartha Institute of Technology\&Sciences,

application may also oMMCs in making car elements, for example, cylinders, chamber sleeves, associating poles and brake plates. Numerous analysts (Subra Suresh 2010, Kevorkijan 1999; Rohatgi 2010; Nakanishi, 2010) have added the MMC software for car parts and assembling achievability of such materials. Surappa (2014) has displayed a diagram of the aluminum grid composite material framework on angles figuring out with the preparing, miniaturized scale, properties and applications. Difficulties to utilize MMC as growing excessive caliber and fortifications of minimum effort, trustworthy and financial advancement of non-risky convenient unit to quantify the undesirable deformities, modest grow more apparatuses for machining and cutting and building up the re-cycling advances were investigated.

\section{TECHNIQUE}

paintings concentrated mechanical plan mechanization programming is, parametric sturdy displaying tool depending on configuration consists of that profit via the simple to learn TM window graphical UI. We could make a 3-D strong model is absolutely companion with or without while the usage of programmed or patron characterized members of the family to catch shape motive.

Parameter esteem alludes to the requirement that comes to a decision the form or geometry of the version or get collectively. Parameters can be either numeric parameters, for instance, line period or distance throughout of the circle, or the geometric parameters, for example, digression, parallel, concentric, even or vertical, and so on. The numerical parameters may be related with one another the usage of the relationship, which enables them to capture plan intention

A version Solid Works incorporates of components, gatherings, and drawings

Commonly, we begin with a comic strip, made fundamental highlights, and in a while upload greater highlights to the version. (You can likewise begin with the imported floor or sturdy geometry).

We are allowed to enhance our plan to include, trade, or reordering highlights.

Drum Brake determinations

Unladen car mass $=4540 \mathrm{~kg}$

Loaded car mass $=8300 \mathrm{~kg}$

Tire transferring span $=389 \mathrm{~mm}$

The coefficient of grinding $(\mu)=0.36$

shoe contact point $=95.5^{\circ}$

Published By:

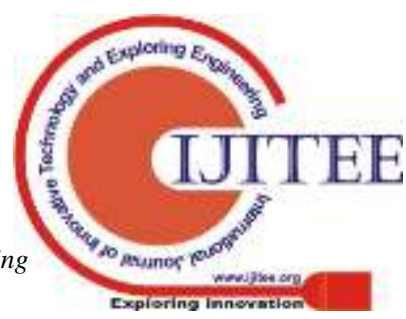


Shoe width $=120 \mathrm{~mm}$

Turn on the brake inward dimension $=416 \mathrm{~mm}$

Outer brake drum measurement $=470 \mathrm{~mm}$

width $=178 \mathrm{~mm}$ drum brakes

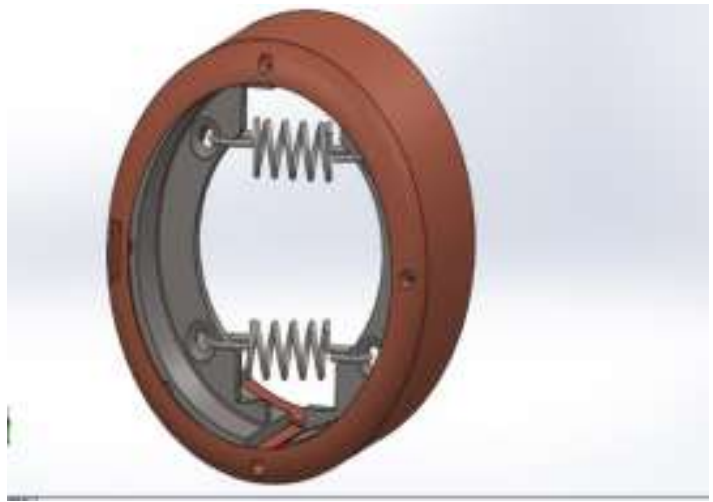

Fig no; 2.4 3D medalling View

Film coefficient convection coefficient $=0.001 \mathrm{~W} / \mathrm{mm}^{\circ}$ C2 Thermal development $=9 \times 10-6 /{ }^{\circ} \mathrm{C}$ Density $=7.822 \times$

$10 \mathrm{Kg} / \mathrm{mm} 6$ three Specific warmth $=410$ Joules of heat conductivity (okay) $=0.0544 \mathrm{~W} / \mathrm{mm}^{\circ} \mathrm{C}$

In the nice and cozy exam, 3 numerous rib width of $8 \mathrm{~mm}$, $10 \mathrm{~mm}, 12 \mathrm{~mm}$ and three unique substances, for instance, Cast Iron, Aluminum and Aluminum Composite taken into consideration one after the other.

Pivot symmetric model of plate brake rotors are made with a backbone width of $8 \mathrm{~mm}$.

So as to make a circle brake, the line became made as appeared in Figure three.

Models brought on should to get four aspects to deliver regions.

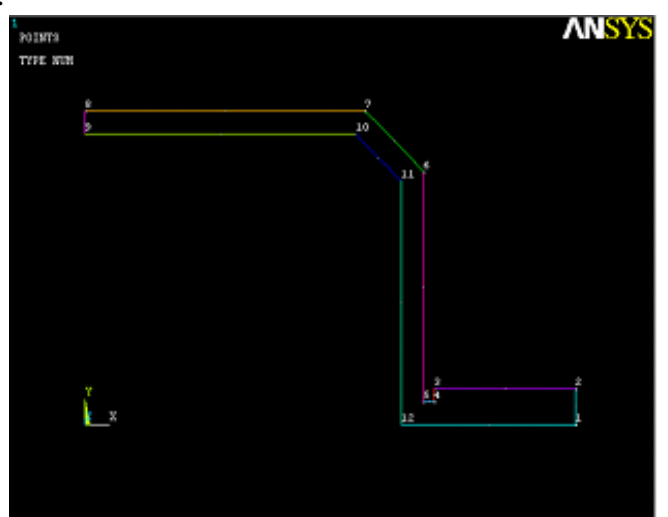

Figure 3 Creation of Lines of Disc Brake Rotor

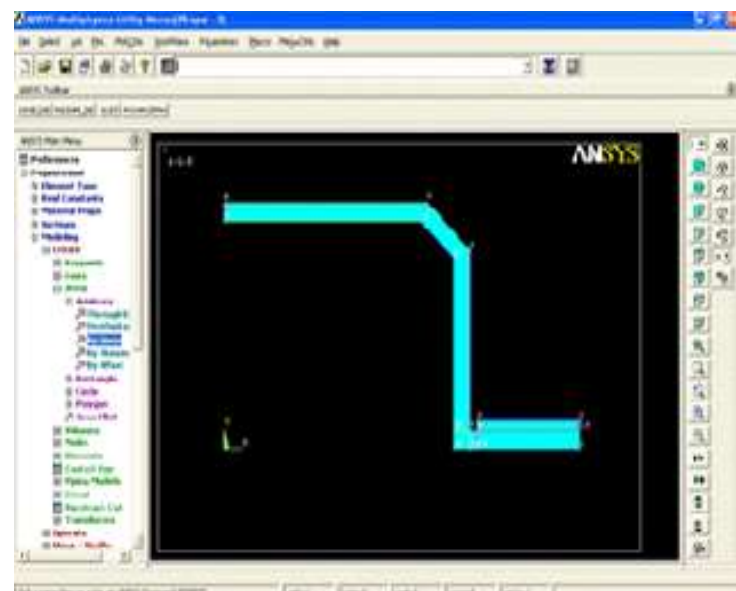

Figure 4 Creation of Areas through Lines
So as to work the model, the sort of issue for decent exam of flying machine Considered 55. Following the production of the territory and the task of the element type, this version together with the department line 10 on all aspects as seemed in Figure

\section{RESULTS AND DISCUSSION}

The results examined below are $8 \mathrm{~mm}, 10 \mathrm{~mm}$ and $12 \mathrm{~mm}$ wide rib fabricated from Cast Iron, Aluminum and Aluminum composites. These results were gotten after heat and basic limit situations applied to the model and the research is completed. The base and maximum extreme temperature and strain are translated as colors, as an example, blue to the base, medium temperature and green to red to the finest.

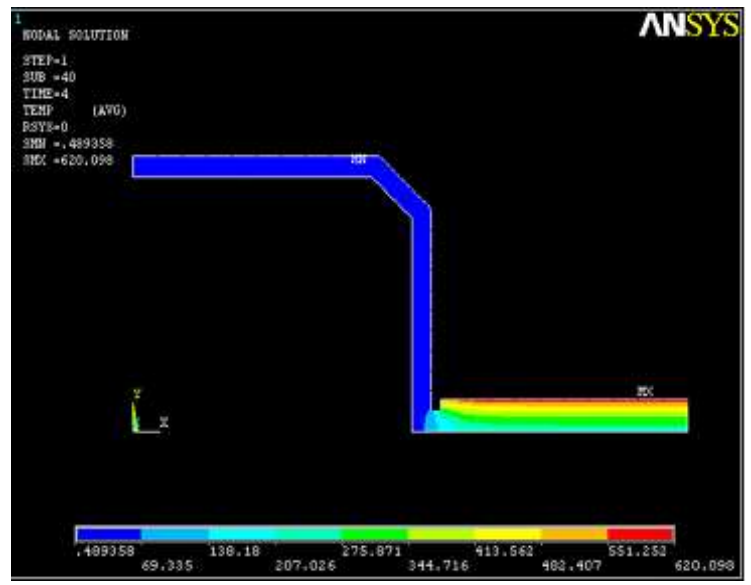

Figure 8 Screenshot of Nodal temperature for rib width of $8 \mathrm{~mm}$ bogus of fashioned iron

The Figures 8 and 9 introductions temperature for rib width of $8 \mathrm{~mm}$ bogus of strong iron. As glares from the screen captures, the base temperature is spoken to in blue, is the temperature of $0.489 \mathrm{~K}$ and is in purple is $620.090 \mathrm{~K}$. It is likewise clear from the screen captures that the temperature dissemination of careless appropriated along the rib time frame and mainly it is towards the surface of the flange.

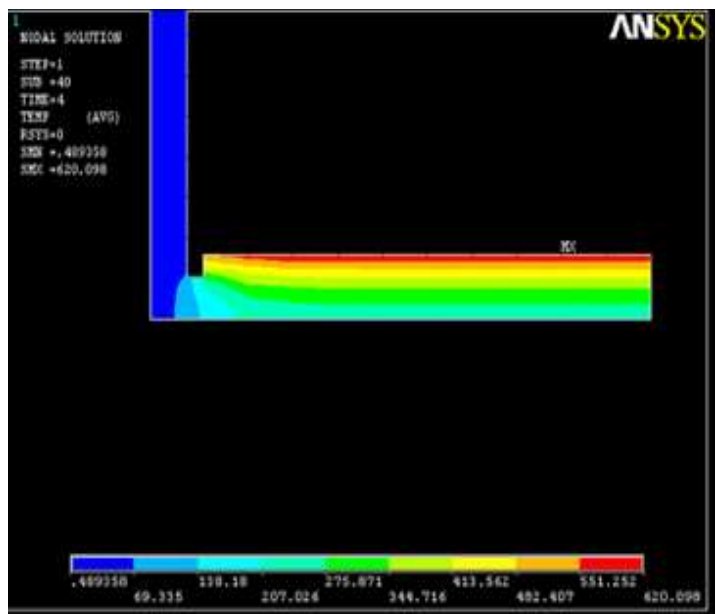

Figure 9 Close view of Nodal Temperature for $8 \mathrm{~mm}$ flange width made of Cast Iron 


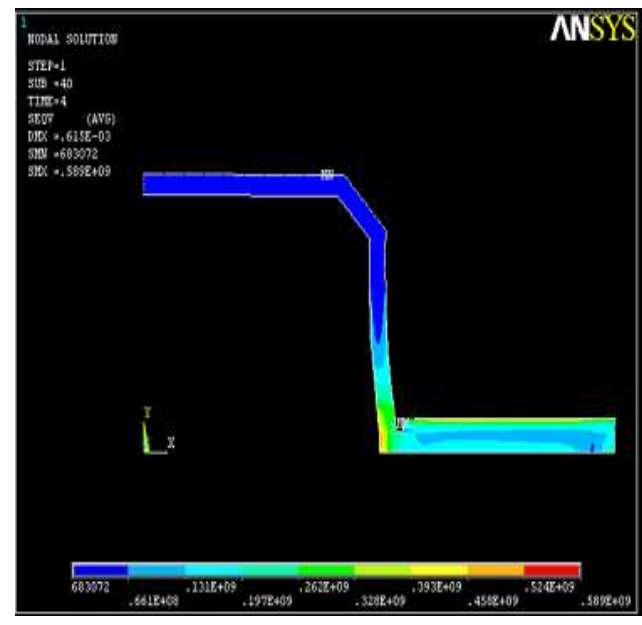

Figure 10 Screenshot of Von Mises Stress for $8 \mathrm{~mm}$ flange width made of Cast 55 and Plane 42 through ANSYS11.0 software.

Plus a discipline inspection executed on the brake rotor plate with a ramification of backbone width of $8 \mathrm{~mm}, 10 \mathrm{~mm}$, $12 \mathrm{~mm}$ and

\section{CONCLUSION \& DISCUSSION}

Accompanying tip drawn from this study:

Investigations 2. Axis-symmetric brake plates had been performed utilizing Aircraft

three. Different materials, for instance, cast iron, aluminum and aluminum composite.

Four. An research is whole heat while utilising time soon be part of process for usage of braking power because of erosion for a period of 4 seconds for a wide range and form of materials.

5. A u . S . Without stopping extra exam blended with warm investigations executed for distinct widths and distinct substances.

6. The consequences are anticipated to be around and broken.

7. Circulation temperature at the least until the circle within the brake rotor on the touch surface is considered $413.183^{\circ} \mathrm{K}$ to $12 \mathrm{~mm}$ extensive slats manufactured from forged iron.

8. Static basic investigations completed via coupling the warm setting with extra exams. Basic Von Mises strain visible $415 * 106 \mathrm{MPa}$ to $12 \mathrm{~mm}$ spine width made of solid iron.

Nine. Comparing the various outcomes received from the examination, with a very nicely may be assumed that the brake rotor plate with $12 \mathrm{~mm}$ spine width and forged iron substances are most best mix.

\section{REFERENCE}

1. Rittner (2001) has added the usage of composite lattice metal barrier,

2. Robert (2001) have shown diverse kinds of aluminum amalgam and their applications.

3. Many researchers (Subra Suresh, 1993, Kevorkijan 1999; Rohatgi2010; Nakanishi 2002) has exhibited the usage of MMC for vehicle components and make feel of the assembly of those substances

4. four. Kennedy et al (1997) have tested the first-rate of the tribological based totally copper particulate silicon carbide composite steel mesh inserted from a closed copper silicon carbide particles.

5. Blanco et al (1997) have proven the structure, homes, programs and operational conduct of carbon - carbon brakes circle.

6. Zaidi et al (1999) had been considered a behavioral grinding drum brakes carbon skeleton square / brake at excessive shear charges beneath high applied masses.

7. Ding et al (2000) have been structured and produce a front brake rotors with a semi-sold fluid blending further to the manufacturing manner.

8. Goni et al (2000) have encouraged that the high fees of coping with the MMC, as a great impediment to make use of it in a car software.

9. Nine. Czichos and Ludema (1992)). Deuis et al (1997) has brought a survey on aluminum composite sliding dry clothes.

10. Kwok et al (1999) have recorded their exam of the special contraptions as rugged put on and delamination put on, blend scratched vicinity, 